FIG. 2.

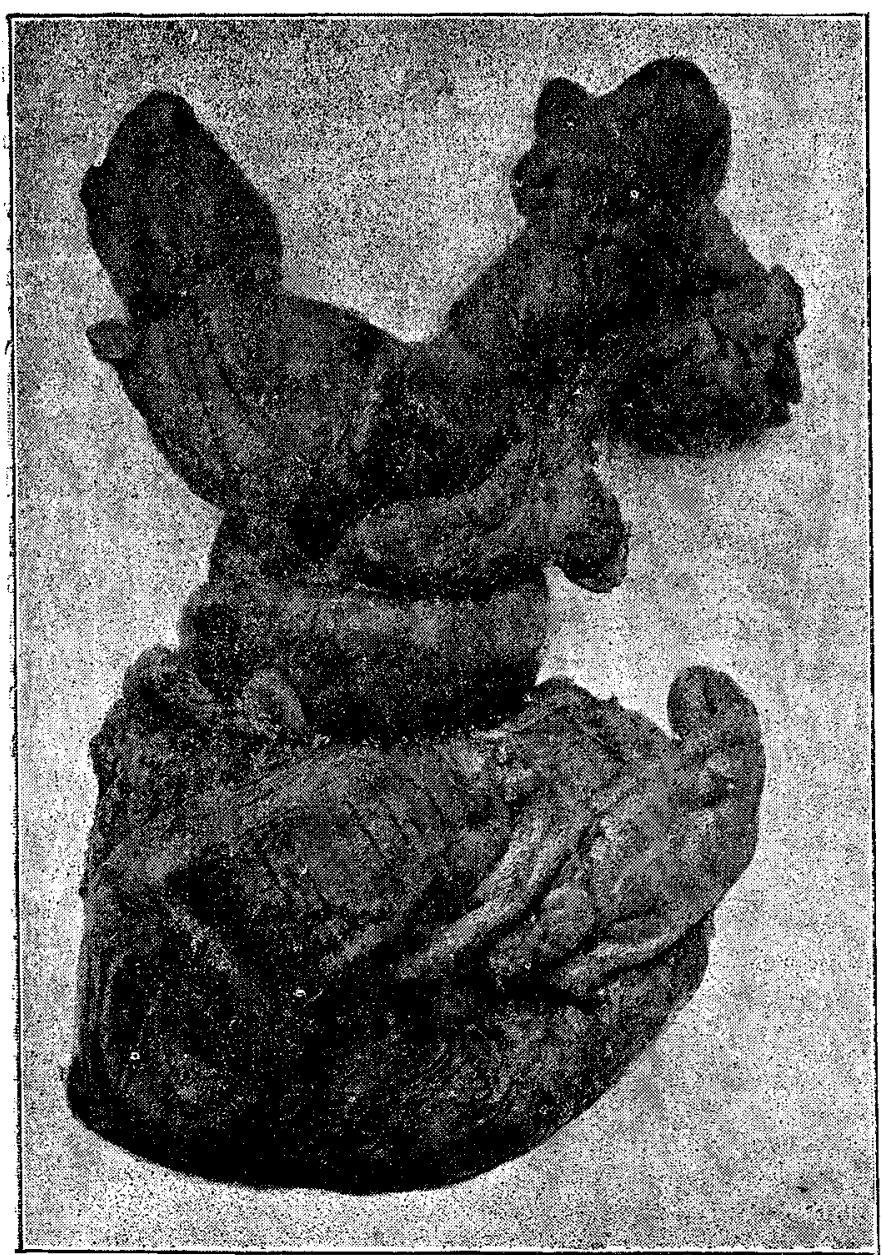

Posterior view of the same

large intestine had thus been produced, the constricting portion being the small intestine. The digestive tube had thrown itself into a slip-knot and it is difficult to imagine how this extraordinary state of affairs could have been produced. The attachments of the cæcum were probably loose in character, which may have accounted for two previous attacks of abdominal pain and tympanites which she had had in 1901, but the knot described must have been of recent formation, as no signs of plastic peritonitis were evident.

Chichester.

\section{THE TREATMENT OF TETANUS BY INTRAVENOUS} SALINE INFUSIONS.

By Vincent S. Hodson, M.B., B.CH. Oxon.,

IATE RESIDENT MEDICAL OFFIOER AT THE KASR-EL-AINI HOSPITAL, CaIRo.

IT seems to me worth while recording some fairly successful cases of tetanus treated by the above method inasmuch as the ordinary methods--viz., antitoxin, chloral, and bromide-are far from satisfactory, and though my cases are only three in number yet the immediate result was so striking that I feel encouraged to send them for publication.

CASE 1.-The patient was an Egyptian fellah who had had masseter spasm for 12 days before admission to the Kasr-el-Aini Hospital, Cairo. He was treated vigorously with antitoxin for the first two days in hospital, but as his condition seemed to me to get worse I on purely empirical grounds bled him 15 ounces and infused two kilogrammes of normal saline solution containing 75 grammes of brandy under complete surgical anæsthesia. Before his recovery from anæsthesia' I gave him a dose of antitoxin and injected half a grain of morphine subcutaneously. After very profuse sweating he slept quietly and when I saw him next day had only very slight spasm of the masseters, which disappeared in a few days.

CASE 2.-This was a case of acute tetanus following on a tramway accident in which the patient lost both leg in the neighbourhood of the knees. About a week afte admission to hospital tetanic spasms came on and whe these had lasted tive days and the patient's condition we very serious I heard of the case and with the permission c Mr. F. C. Madden, to whom I am indebted for this case, infused him, bled him, and injected serum and morphine : in Case 1. This was followed by sleep for eight hours an complete cessation of spasm until about $4 \mathrm{~A} . \mathrm{M}$. next mor ing, that is, 16 hours in all. Spasm, however, returned wit great rapidity and so I infused him again with the sar. result, but death ensued 24 hours later. This case wi rather a severe test, as the man was quite young and ver poorly nourished and was recovering from a very sevel accident. The origin in this case was thought to be in stitch which suppurated for a few days and then heale under treatment.

CASE 3.- This case was very similar to the first one anc as in that case, there was no history of wound. 'This absenc of history is not to be wondered at as the fellaheen, for tr most part, do not know their own ages and have practical] no powers of memory or observation. Seven days of in creasing spasm was the history obtained and shortly aft. admission to hospital I infused him with two kilogrammes . saline solution and 75 grammes of brandy and gave him th same injections as in the other cases. With the exception. very slight masseter spasm next day there was no return . symptoms and the patient was discharged after a short stc in hospital quite well.

Though not claiming that this treatment is a certain cur the record of the above cases shows that it undoubted exercises a profound influence on the condition of spasr and if added to the treatment of tetanus recommendt in THE LANCET of August 6th, 1904, p. 386, will, I hop help to reduce the present very heavy mortality that quoted by the authorities.

Hony Bimbashi.

\section{g dutrinor}

\section{HOSPITAL PRACTICE, BRITISH AND FOREIGN.}

Nulla autem est alia pro certo noscendi via, nisi quamplurimas molla sutem est alia pro certo noscendi via, nisi quamplum morborum et dissectionum historias, tum aliorum tum propr collectas habere, et inter s
Morb., lib. iv., Procmium.

\section{CHESTERFIELD AND NORTH DERBYSHIR HOSPITAL}

A CASE OF TRAUMATIC TETANUS WHICH RECOVERED UND: TREATMENT BY HYPODERMIC INJECTIONS OF CURARE.

(Under the care of Mr. W. J. SYMES.)

For the notes of the case we are indebted to Dr. J. Connolly, house surgeon, and Dr. W. B. Cullen, assista house surgeon.

On June 12th, 1904, a youth, aged 16 years, was admitt to the Chesterfield and North Derbyshire Hospital, with t history of having had his right leg crushed by the wheel a wagon while at work in a coal-pit on June 3rd, causing superficial ragged wound, about two by one and a half inch. in the popliteal space. He was taken home and seen $t$ same evening by Mr. J. A. Magee of Clowne, near Chesterfie: who dressed the wound which progressed satisfactorily un the 10th when the patient was seized with spasm of $t$ muscles of the neck and jaw, followed by difficulty swallowing. A diagnosis of tetanus was made and $N$ Magee gave two injections of antitetanic serum, ten cul centimetres each, before sending him to the hospital the 12 th.

On admission at 2 P.M. there was found marked rigid; of the muscles of the jaw, neck, and abdomen. He w unable to separate the teeth, risus sardonicus was prese to some extent, and he was sweating profusely. The te: perature was $99.8^{\circ} \mathrm{F}$., the pulse was 88 , and the respiratio were 32 . He was put to bed, ten cubic centimetres of an tetanic serum were injected subcutaneously at 4.30 P.M. $t$ same evening, the wound was thoroughly cleansed, and carbolic compress, 1 in 40, was applied and changed eve 
four hours. He continued much the same till June 14th, when he had a tetanic convulsion at 4.45 P.M. and ten cubic centimetres of serum were injected at 6.30 P.M., to be followed at 8 P.M. by another attack. The spasms were controlled by chloroform. Between midnight on the 14th and $5 \mathrm{~A}$.M. on the 15th, at intervals of rather less than an hour, the patient had seven very severe tetanic seizures, in some cases with opisthotonos, during which respiration was seriously interfered with, and chloroform was freely administered, artificial respiration being resorted to during the worst attacks. Bromide and chloral given per rectum produced no apparent benefit.

Any attempt to feed the patient or to touch him at this period brought on a spasm and he was therefore left as quiet as possible till at 5.15 P.M., June 15th, on trying to pass a nasal tube for feeding purposes, another violent convulsion was induced. He was again anæsthetised and 30 grains of chloral hydrate were passed by the stomach tube. This was retained and the patient slept quietly for several hours. $\mathrm{He}$ felt better on waking and was able to take liquid nourishment by the mouth but was unable to separate the jaws. He continued to be more comfortable until 2 P.M. on the 16th, when he had a slight spasm from tarning himself in bed. He was given 15 grains of chloral hydrate by the mouth and was quiet again till 1 A.M. on the 17 th, when he had another slight spasm for which a similar dose was administered. The highest temperature recorded was on the 15 th when it reached $101.6^{\circ} \mathrm{F}$. at 2 P.M. The pulse was 104 The patient sweated profusely during the attacks and thirst was extremely marked. The wound was now dressed with a strong solution of sanitas in the hope of inhibiting the development of fresh organisms.

On June 19th it was decided to try curare and at 6 P.M. one-twelfth of a grain was given subcutaneously. He had a spasm at 1 A.M. on the 20th, for which a further onetwelfth of a grain was injected at 1.20 A.M., after which he remained free till $8.45 \mathrm{~A} . \mathrm{M}$., when another seizure took place for which he was given 20 grains of chloral hydrate at 8.55 A.M. At 4.40 P.M. a fresh attack came on and curare one-sixth of a grain, was injected at 5.40 P.M. He had a slight spasm at 8.30 P.M. and again at 8.45 P.M. 30 grains of chloral hydrate were given by the stomach tube under chloroform. At 9.15 P.M. ten cubic centimetres of serum were injected, but another sharp spasm came on at 11.15 P.M., followed by slight attacks at intervals of about two hours, until at 5 P.M. on the 21 st he had a very severe convulsion, which as usual was controlled by chloroform. A similar event occurred at $1.10 \mathrm{~A} . \mathrm{M}$. on the $22 \mathrm{nd}$ and one-third of a grain of curare was injected at 1.15 A.M. Except for the constant state of rigidity of the muscles he was now fairly comfortable. Slight spasms manifested themselves at 4.40 and 4.50 P.M. on the 22 nd and at 6.5 P.M. he was given half a grain of curare. At 10.20 P.M. 30 grains of chloral hydrate were administered by the stomach tube under chloroform to induce sleep and at 1.35 A.M. on the 23rd two-thirds of a grain of curare were injected. The patient felt better after this, the jaws could be separated slightly, and he was free from spasms, but as a precautionary measure five-sixths of a grain of curare were injected at $1.15 \mathrm{~A}$.M. on June 24 th with steady improvement and the same night at 8.20 one grain of curare was given. The temperature this day was $100^{\circ} 4^{\circ}$, the pulse was 120 , and the respirations were 54. The teeth could now be separated fully a quarter of an inch and in order to see whether any change would occur the curare was discontinued. June 25th passed uneventfully, but at 6.30 P.M. on the 26 th another severe convulsion made its appearance, with close apposition of the teeth once more. At 6.45 P.M. one grain of curare was injected and the same dose was repeated at 1.35 A.M. on the 27 th without recurrence of spasm. The jaws could again be separated as before and accordingly curare was continued once every 24 hours in increasing doses up to two and a half grains at 1.30 A.Mr. on July 1st, when very marked improvement set in. From this date a daily administration of one grain of curare was kept up until the 9th, when he was able to use his jaws to masticate food, and then half a grain till the 20 th, with steady reduction in the tonicity of the muscles. Active treatment was discontinned after July 20th, he developed an excellent appetite, and put on flesh rapidly. The patient was placed out-of-doors on June $27 \mathrm{th}$ in a recumbent position to have the advantage of the bright sunshine and daily afterwards when weather permitted. A month after the onset of tetanus he was able to walk about and on Angust 13th he left the hospital quite well.
Remarks by Dr. ConNoliy and Dr. CuLLLAN, - 'the case presents some features of interest, viz.-(a) Incubation period (seven days). Some recent statistics have placed the mortality at 96 per cent. in cases where tetanus manifests itself under ten days after injury. (b) Number of spasms: 16 severe and 14 less severe, 30 altogether. (o) Marked improvement under treatment with curare and recurrence of the spasms when it was stopped during the active stage of the disease. In all 26 ? grains of curare were given hypodermically. No ill effects on the heart were observed and the patient said that he felt more comfortable and could breathe more easily after the injections.

Mr. W. J. Symes, under whose care the patient was admitted, has kindly permitted us to record these notes.

\section{WEST CORNWALL MINERS' AND WOMEN'S HOSPITAL, REIDUTH.}

CASES OF ABDOMINAI SECTION PERFORMED FOR INTUSSUSCEPTION AND PERFORATING GASTRIC ULCER.

(Under the care of Dr. JoHN H. Tonking.)

IN these cases, which were three in number, one patient suffered from intussusception and the other two from perforating gastric ulcer. The case of intussusception terminated fatally; of the other two patients one recovered and the other succumbed on the eleventh day after an operation for subphrenic abscess. Including these, three operations for perforation, all performed by Dr. Tonking, have taken place at this hospital during the last 12 months.

CASE 1.-The patient was a man, about 40 years of age, who was seized with acute abdominal pain on Jan. 18th. There was great tenderness equally in the appendicular region and in the epigastrium and hot opium fomentations were applied at 1 P.M. At 6 P.M., as no relief was felt, a consultation was held with Dr. Frank Hichens of Redruth, when perforation was diagnosed, and as the man's wife admitted having had considerable difficulty with regard to his food the perforation was considered to be probably in the wall of the stomach, although there was marked appendicular tenderness. The liver dulness was normal and there was no vomiting; the abdomen was absolutely rigid and typical facies was present. At 9 P.M. ether was administered by Dr. William Blackwood and assisted by Dr. Hichens Dr. Tonking opened the abdomen. Gas immediately escaped and a perforation was found at the pyloric end of the stomach close to the lesser curvature. The abdomen was swabbed but no irrigation was used as there was no extravasation. The position rendered tucking in difficult, and partly by turning in and partly by stitching the omentum over the perforation was closed by a double layer of fine silk sutures. A drainage-tube with a gauze wick leading to the perforation was placed in the wound after swabbing the parts dry without irrigation and the wound was closed. The usual rectal feeding was employed for five days with the addition of strychnine when required. The temperature, however, did not come down but remained between $100^{\circ}$ and $101^{\circ} \mathrm{F}$. for a week when dulness was discovered at the right base. This increased and on the tenth day, after exploring with a needle in the ninth interspace, pus was let out by excising a portion of the tenth rib. The temperature still did not come down and the patient died on the next day. There were no stomach symptoms and the abdominal wound had practically healed.

CASE 2.-The patient was a youth, aged 19 years. He was staying in Camborne for Easter Monday and after dinner was walking in the town when he was seized with agonising pain in the abdomen for which each of his friends suggested a different variety of spirit. After taking whisky, brandy, rum, and gin without relief he was put into a cab, in the bottom of which he lay doubled up, and was in this way taken home. Dr. Tonking was informed that he had suffered for months from distress an hour or more after meals. The abdomen was board-like. There was repeated vomiting of material having a spirituous odour. The liver dulness was normal. The patient was removed to the hospital and after arrival there the liver dulness was found to have disappeared. At 8 P.M.-namely, five hours after the attack-ether was administered by Dr. Blackwood and Dr. Tonking, assisted by Dr. Hichens, opened the abdomen. There was an immediate escape of gas and a small perforation of the size of a pea, which was found near the pylorus at the lesser curvature, was tucked in 